\title{
Towards Sustainable Machining of Inconel 718 Using Nano-Fluid Minimum Quantity Lubrication
}

\author{
Hussien Hegab * and Hossam A. Kishawy \\ Machining Research Laboratory (MRL), Faculty of Engineering and Applied Science, \\ University of Ontario Institute of Technology (UOIT), Oshawa, ON L1H 7K4, Canada; Hossam.Kishawy@uoit.ca \\ * Correspondence: Hussien.Hegab@uoit.net; Tel.: +1-905-721-8668 (ext. 5794)
}

Received: 9 July 2018; Accepted: 30 July 2018; Published: 2 August 2018

\begin{abstract}
Difficult-to-cut materials have been widely employed in many engineering applications, including automotive and aeronautical designs because of their effective properties. However, other characteristics; for example, high hardness and low thermal conductivity has negatively affected the induced surface quality and tool life, and consequently the overall machinability of such materials. Inconel 718, is widely used in many industries including aerospace; however, the high temperature generated during machining is negatively affecting its machinability. Flood cooling is a commonly used remedy to improve machinability problems; however, government regulation has called for further alternatives to reduce the environmental and health impacts of flood cooling. This work aimed to investigate the influence of dispersed multi-wall carbon nanotubes (MWCNTs) and aluminum oxide $\left(\mathrm{Al}_{2} \mathrm{O}_{3}\right)$ gamma nanoparticles, on enhancing the minimum quantity lubrication (MQL) technique cooling and lubrication capabilities during turning of Inconel 718. Machining tests were conducted, the generated surfaces were examined, and the energy consumption data were recorded. The study was conducted under different design variables including cutting speed, percentage of added nano-additives (wt.\%), and feed velocity. The study revealed that the nano-fluids usage, generally improved the machining performance when cutting Inconel 718. In addition, it was shown that the nanotubes additives provided better improvements than $\mathrm{Al}_{2} \mathrm{O}_{3}$ nanoparticles.
\end{abstract}

Keywords: Inconel 718; minimum quantity lubrication; nano-fluid; surface roughness; energy consumption

\section{Introduction}

Nickel based alloys have unique properties, such as high erosion resistivity, high melting temperature, and high capability to resist thermal fatigue and shock. During cutting of nickel-based alloys, the low heat conductivity prevents an efficient disposal of the heat generated through the workpiece and chips, which leads to high temperature that negatively affects the tool performance [1,2]. It has been shown that the increase in the cutting temperature over $650{ }^{\circ} \mathrm{C}$, leads to low surface quality, excessive tool wear, microstructure change, and variations in the micro-hardness [3,4]. Another challenge is the strain hardening when cutting nickel-based alloys because, of the existence of some elements in the material such as molybdenum and niobium. Generally, it has been shown that machining of nickel alloys is related with insufficient surface integrity characteristics, and poor tool wear behavior [5-7]. The two main reasons for employing a cutting fluid during machining are to decrease the induced cutting temperature in shear zones and deliver a lubrication to reduce the friction in the tool-workpiece interface area. Various studies showed that minimum quantity lubricant (MQL) is a potential alternative to flood cooling that minimizes the cutting fluid amount delivered to the cutting interface area $[8,9]$. However, MQL is not an efficient replacement of flood coolant, particularly when cutting titanium and Inconel. One way to improve the cooling and lubricant functions of MQL is using 
nano-fluids, which enhance the base fluid thermal, and wettability aspects [7-10]. Carbon nanotubes (CNTs) and aluminum oxide $\left(\mathrm{Al}_{2} \mathrm{O}_{3}\right)$ gamma nanoparticle, are among the nano-additives that have superior properties. The diameters of these nano-additives, vary from a few nano-meters to hundreds of nano-meters, and CNTs length ranges between tens of nanometers to several centimeters [11]. With a remarkable combination of mechanical properties and an acceptable price, along with superior properties including excellent thermal conductivity, and high strength and stiffness [12]; this makes the proposed nano-fluid a good alternative. These properties provide the resultant nano-fluid the ability to withstand the high-generated temperature during the machining of difficult-to-cut materials. In addition, they would enhance the nano-fluid tribological functions as the applied nano-additives work as spacers in the workpiece-tool interface area, to reduce the induced friction during machining processes. The superior properties of the used nano-fluids, help in dissipating the excessive generated heat when machining such difficult-to-cut materials, and that would improve the tool life, enhance the surface quality, and reduce the generated energy consumption. Nano-cutting fluids technology, has been used in previous studies to enhance the machining process performance, for example, micro-drilling of aluminum 6061 [13] sing nano-diamond particles; micro-grinding of tool steel using aluminum oxide-nano-particles [14]; and micro-end-milling of Ti-6Al-4V using MQL-nano-fluid with chilly $\mathrm{CO}_{2}$ gas [15]. In addition, previous studies obtained better results when using MQL-nano-fluid compared to the classical MQL; for example, better surface quality [16] and flank wear [17] results were noticed when machining Ti-6Al-4V using MWCNTs-MQL. Furthermore, MWCNTs-MQL showed improvements in the tool wear behavior when turning Inconel 718 [18]. Moreover, lower cutting forces and better surface quality were noticed when turning EN 31, using MWCNTs-MQL [19]. However, only a few studies have examined their effects on different machining operations. The novelty here, focuses on improving the MQL potential to dissipate heat using MQL nano-mist, to environmentally enhance the Inconel 718 machinability. In addition, reviewing the open literature has shown that there is no-previous attempt in using MQL-MWCNTs-nano-fluid in enhancing the machinability of Inconel 718. This work aimed to explore the influence of dispersed multi-walled carbon nanotubes (MWCNTs) and aluminum Oxide $\left(\mathrm{Al}_{2} \mathrm{O}_{3}\right)$ gamma nanoparticles, into vegetable oil using the minimum quantity lubrication (MQL) approach when machining Inconel 718. The selection of these nano-additives types, is mainly related to their superior cooling and lubrication characteristics, which would improve the resultant nano-fluid, and the tribological and heat transfer properties. The proposed hybrid strategy is an environment friendly alternative to the traditional flood coolant with synthetic oils. Our investigations included power consumed during the cutting process, and surface quality.

\section{Experimentation and Methodology}

To understand and analyze, the influence of dispersed MWCNTs and $\mathrm{Al}_{2} \mathrm{O}_{3}$ nanoparticles on the MQL performance, different cutting tests were done with different levels of cutting feed rate, weight percentages of added nano-additives (i.e., MWCNTs or $\mathrm{Al}_{2} \mathrm{O}_{3}$ nanoparticles), and cutting speed. Bar turning experiments were done using a CNC lathe machine (Hass ST-10 CNC). Inconel 718 (ASTM SB 637) was utilized as the used workpiece. The depth of cut was $0.2 \mathrm{~mm}$, the cutting length was $50 \mathrm{~mm}$, and the information of the used cutting insert, is listed in Table 1 . The air-oil mixture was supplied by a stand-alone booster system (Eco-Lubric), which was installed on the machine tool with a nominal fluid flow rate of $40 \mathrm{~mL} / \mathrm{h}$, whilst the applied compressed air had a pressure of $0.5 \mathrm{MPa}$. During the experimentation phase, the used base cutting fluid was ECOLUBRIC E200 (vegetable oil), which provides less abrasive effects on the environment. The position and the angle of the MQL nozzle, were adjusted by experimental observation to avoid being blocked by chips. However, more investigations are still required to study the influence of other MQL variables (e.g., nozzle angle, distance, and flow rate). To ensure that the tool was not worn, the flank wear was measured after each cutting test, whilst the maximum allowable flank wear was $0.3 \mathrm{~mm}$. In this work, the flank wear was used to evaluate and assess the tool performance, as it is considered as one of the significant wear modes when machining nickel-based alloys [20,21]. In addition, the cutting tests were repeated three 
times for each run to ensure reliable results. A sensitivity analysis of cutting performance results was employed to select the cutting conditions values, for cutting speed and feed rate levels. During the experimentation phase, multi-walled carbon nanotubes (MWCNTs) that had $94 \%$ purity, $10-30 \mu \mathrm{m}$ length, 12-20 nm average diameter, and $110 \mathrm{~m}^{2} / \mathrm{g}$ specific surface area were employed for nano-cutting fluid preparations. Furthermore, it should be stated that nano-additives dispersion into vegetable oil is a significant issue, which influences the thermal, rheological, and heat transfer characteristics of the proposed nano-fluid (e.g., thermal conductivity and viscosity). On the other hand, $\mathrm{Al}_{2} \mathrm{O}_{3}$ nano-powder properties were; $20 \mathrm{~nm}$ size, $95 \%$ purity, and $138 \mathrm{~m}^{2} / \mathrm{g}$ specific surface area. An ultrasonic device (AQUASONIC-50HT) was used to disperse the nano-additives into the cutting oil over a period of $3 \mathrm{~h}$ at $60{ }^{\circ} \mathrm{C}$, and then a magnetic stirrer (Hot Plate Stirrer-3073-21) was used for the stirring step for $30 \mathrm{~min}$ to confirm fully, dispersion of used nano-additives into the base cutting fluid. In addition, sodium dodecyl sulfate (surfactant) of $0.2 \mathrm{gm}$ was employed in preparing the nano-fluid. The surfactant's main function was to enhance the stability of the resultant nano-fluid to be more hydrophilic, and to increase the nano-additives surface charges; therefore, the repulsive forces between the nano-additives were increased as previously illustrated in references [22,23]. After each cutting test, surface roughness (Ra), and energy consumption data were collected. Surface roughness tester (Mitutoyo SJ.201) was used to measure the average surface roughness $(\mathrm{Ra})$ after each cutting pass. The used cut-off length was $0.8 \mathrm{~mm}$. After each cutting test, the surface roughness tester was used in five random regions along the machined surface, and the average value was considered. Additionally, a power-sight manager device was used to record the resultant power consumption after each cutting pass. The experimental setup view, is provided in Figure 1.

Table 1. The cutting tool information during machining of Inconel 718.

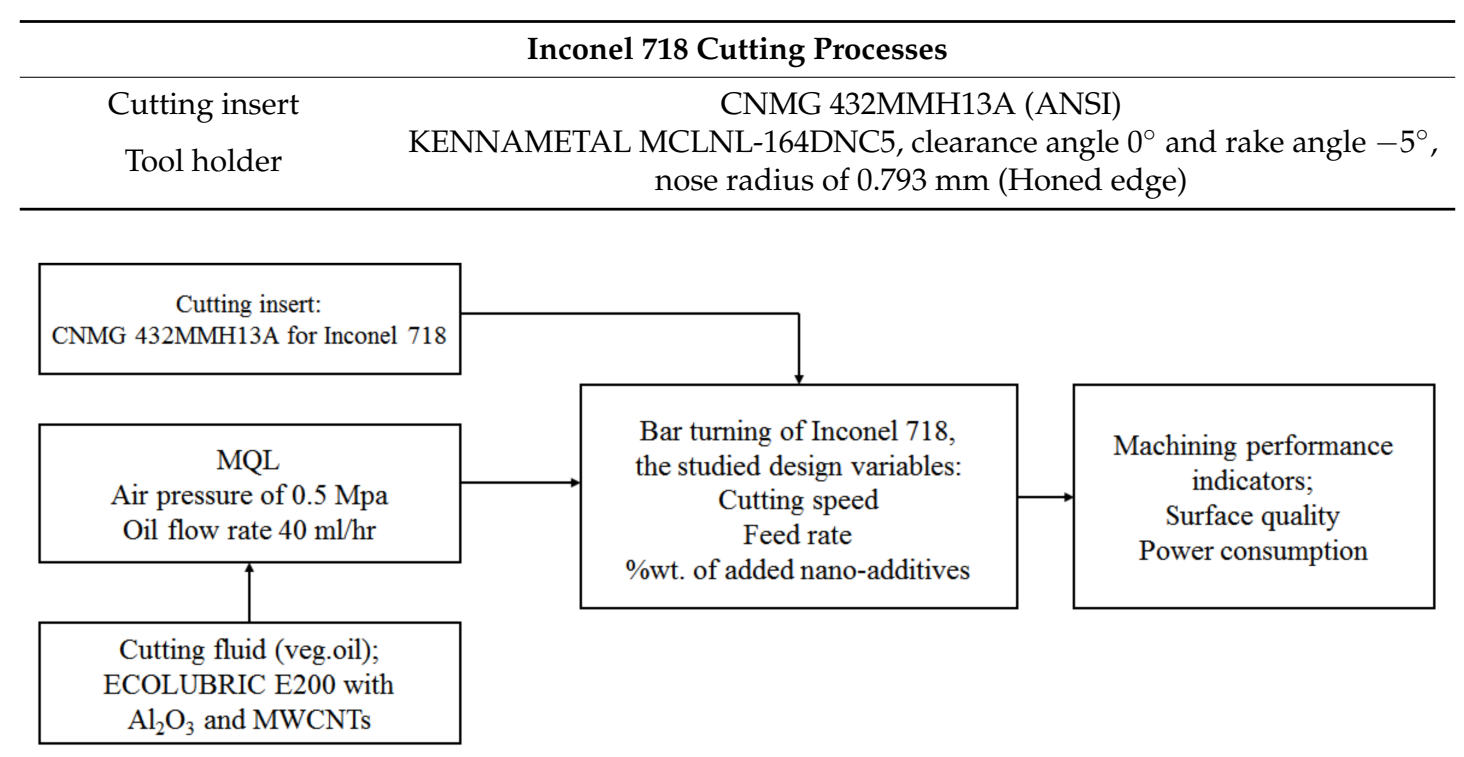

Figure 1. Schematic of the experimentation phase.

In this work, three design variables (i.e., cutting speed, cutting feed, and added nano-additives percentage) were used at three levels each. Table 2 , indicates the design variables to be studied and their corresponding levels, for both used nano-additives (i.e., $\mathrm{Al}_{2} \mathrm{O}_{3}$ and MWCNTs). $\mathrm{L} 9$ orthogonal array (L9OA) based on the Taguchi method was implemented in experiments, as described in reference [24]. L9OA had 9 rows corresponding to the number of tests (degrees of freedom equal to 8). Tests were replicated three times and average response values were calculated. The full factorial array in this work was L27OA $\left(3^{3}\right)$; however, fractional factorial array L9OA based on the design of experiments approach was implemented to save time and costs. 
Table 2. L9OA used in experimentation plan.

\begin{tabular}{cccc}
\hline Cutting Test No. & $\begin{array}{c}\text { Cutting Speed } \\
(\mathbf{m} / \mathbf{m i n})\end{array}$ & $\begin{array}{c}\text { Feed Rate } \\
(\mathbf{m m} / \mathbf{r e v})\end{array}$ & $\begin{array}{c}\text { Added Nano-Additives } \\
(\mathbf{w t} \text { \%) })\end{array}$ \\
\hline 1 & 30 & 0.2 & 0 \\
2 & 30 & 0.3 & 2 \\
3 & 30 & 0.4 & 4 \\
4 & 40 & 0.2 & 2 \\
5 & 40 & 0.3 & 4 \\
6 & 40 & 0.4 & 0 \\
7 & 50 & 0.2 & 4 \\
8 & 50 & 0.3 & 0 \\
9 & 50 & 0.4 & 2 \\
\hline
\end{tabular}

\section{Results and Discussions}

The average surface roughness results when using the two types of nano-additives, are shown in Figure 2. Both types of nano-fluid showed improvement in machined surface quality; however, cutting tests 3 and 9 did not show significant improvements compared to other cutting tests performed using nano-additives, which is attributed to the higher value of feed $(0.4 \mathrm{~mm} / \mathrm{rev})$ used in these two tests. Best surface quality was obtained after test 4 when using $2 \mathrm{wt} . \%$ MWCNTs nano-fluid. When $4 \mathrm{wt} . \%$ of added $\mathrm{Al}_{2} \mathrm{O}_{3}$ nano-particles was applied, it was found that cutting test 7 offered the better surface quality. A comparison between the two types of nano-additives revealed that MQL-MWCNTs provided better performance in enhancing the surface quality; however, both cases (i.e., MWCNTs and $\mathrm{Al}_{2} \mathrm{O}_{3}$ ) provided almost the same performance as cutting test 7 . The results revealed that the cooling and lubrication characteristics of nanofluids, improve the lubrication and wetting characteristics at the rake and flank regions, and accordingly provide better heat dissipation as has been discussed in a previous study [25]. Thus, better average surface roughness values were noticed compared to the cutting tests done without any nano-additives, and these findings confirm the effectiveness of nano-fluids usage in improving the cutting processes performance, as discussed in some previous studies [22,26,27]. Additionally, it should be stated that the lowest feed rate offers the optimal level in terms of the induced surface roughness, while no significant effect has been noticed for the cutting speed. Furthermore, due to the increasing of nano-additive concentration, which increases the number of nano-additives at the tool-workpiece interface; these nano-additives perform a vital role as spacers, decreasing the contact between the tool and workpiece. Consequently, the frictional behavior is improved, and the surface roughness is decreased. Figure 3, shows the energy consumption results when using MWCNTs and $\mathrm{Al}_{2} \mathrm{O}_{3}$ nano-fluids. The lowest energy consumption was demonstrated at cutting test 2 when MWCNTs were used, and test 3 for the case of $\mathrm{Al}_{2} \mathrm{O}_{3}$ nano-particles. In general, lower energy consumption was observed when MWCNTs were used except cutting test 3 which showed lower energy consumption of about $2 \%$ when $\mathrm{Al}_{2} \mathrm{O}_{3}$ nano-fluid was used. The change in the energy consumption when using nano-additives, is mainly due to improvements in the progression of tool wear due to, improvements in the cooling effectiveness, which led to a decrease in the tool material thermal softening [23,28-31]. In addition, the chips flow during machining Inconel 718 takes place within the workpiece (not at the tool-workpiece interface) because of the high induced friction, and hence high cutting force is required. Regarding the optimal levels, the lowest cutting velocity offers the optimal level in terms of the energy, while no significant effect has been noticed for the feed rate. Application of MQL-nano-fluid to the tool-chip interface zone is an effective lubrication technique, as the applied nano-additives play as rollers to improve the frictional behavior, and consequently the nano-additives rolling effect decreases the energy consumption. 


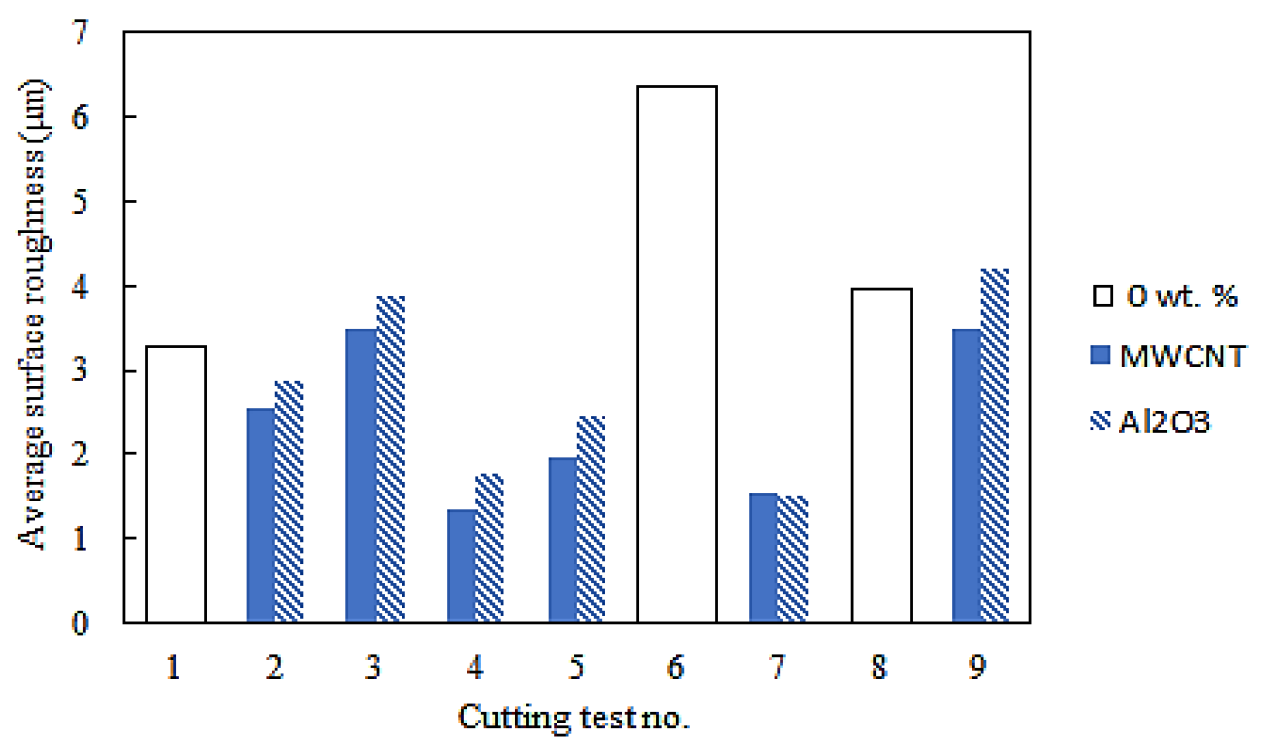

Figure 2. Average surface roughness results.

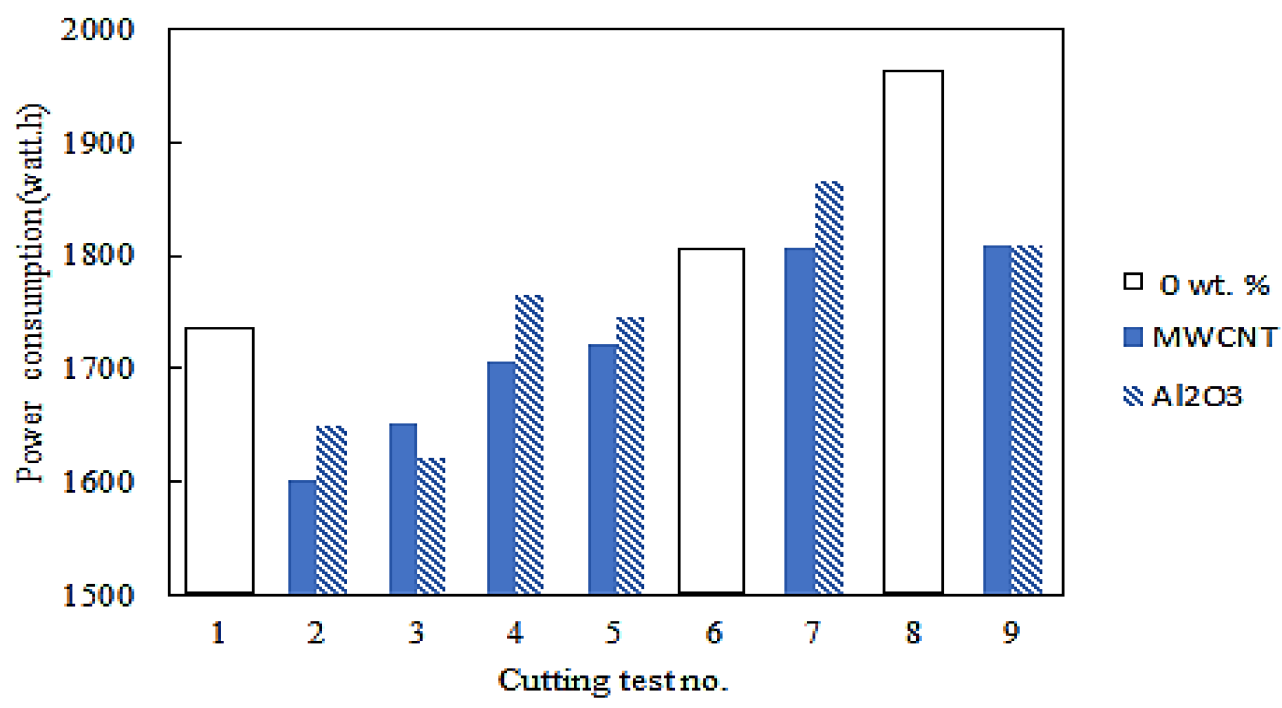

Figure 3. Energy consumption results.

There is no clear physical evidence in the open literature proving that MWCNTs nano-fluid offers better tribological properties than $\mathrm{Al}_{2} \mathrm{O}_{3}$; however, based on current research results, it is claimed that MWCNTs based nano-fluid could offer better performance than $\mathrm{Al}_{2} \mathrm{O}_{3}$ as a lubricant. Thus, studying and understanding the nano-cutting fluids frictional and heat transfer functions is highly required, and is currently under investigation. It is an important aspect to understand the MQL nano-fluid mechanism. The technique schematic, is shown in Figure 4. It can be concluded that the proposed nano-fluids are atomized using the MQL device, under employment of a certain amount of compressed air. Consequently, a fine mist, walled with a vegetable oil layer is formed (see Figure 4) [16-18,32,33]. This mist is capable of penetrating into the tool-workpiece interfere area and creating a tribofilm which has a significant role in reducing the generated cutting heat, as well as decreasing the coefficient of friction. Accordingly, these improvements significantly enhance the cooling and lubrication functions, and maintain the tool hardness for a longer period. Thus, the MQL-nano-fluid showed better performance in terms of tool wear behavior, compared to other cutting tests done using pure MQL without any added nano-additives. 


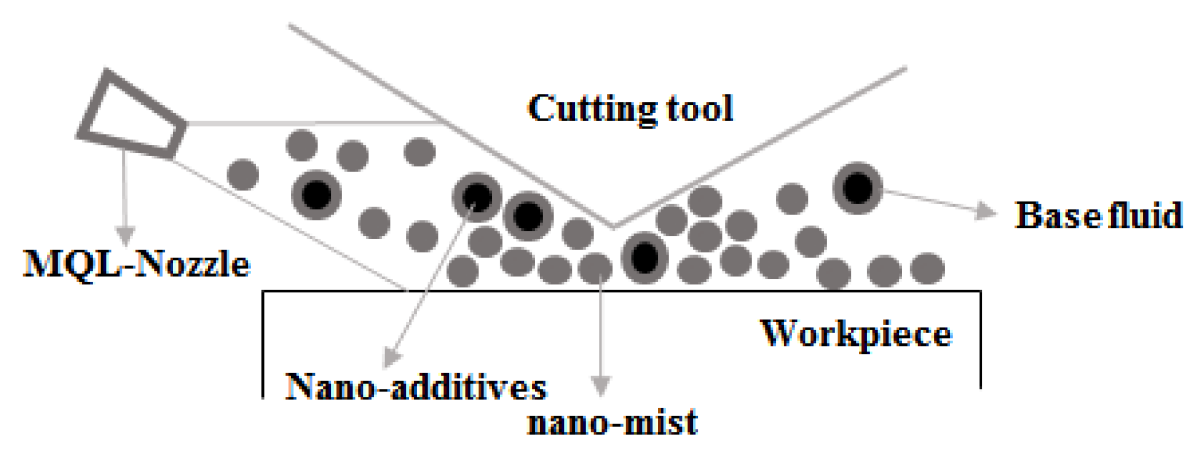

Figure 4. The MQL-nano cutting fluid mechanism (rolling effect) [16-18].

Finally, it should be stated that nano-fluids usage when employing flood coolant can be an environmental concern; however, when using the MQL technique, an optimal amount of oil was used and it resulted in a very fine mist where a certain procedure was followed to eliminate any concern of using the nano-additives. In addition, during the experimentation phase, certain safety procedures (i.e., standard nano-additives safety data sheets), were applied to maintain a standard health and safety level in the workshop to avoid any harmful impacts to the machine operator. Regarding the disposal method, the nano-fluids were carefully filtered before being released in to the sewer according to a standard material safety data sheet [34]. In addition, a standard ventilator was employed in the workspace area to absorb the resultant nano-mist in the surrounding air.

\section{Conclusions}

In this work, two nanofluids (MWCNTs and $\mathrm{Al}_{2} \mathrm{O}_{3}$ ) were employed during machining of Inconel 718 to study their influence on the machinability when MQL technology was used. This research addressed the research gap in the literature, which relates to investigation of MQL-nano-fluid technology when machining nickel-based alloys using both nano-particles and nano-tubes. The study revealed that:

1. Both nanofluids offer better results for surface quality, and energy consumption; however, MWCNTs presents better performance than $\mathrm{Al}_{2} \mathrm{O}_{3}$ nano-fluid. The analysis of the measured surface roughness, and energy consumption results showed that the nano-additives weight percentage has a significant effect on all previous characteristics, either using MWCNTs or $\mathrm{Al}_{2} \mathrm{O}_{3}$.

2. The nano-fluids improvements were mainly due to the superior tribological and heat transfer characteristics of the added nano-additives, which improve the interface bonding between the cutting tool and workpiece surfaces. In addition, the nano-fluids offer a better heat dissipation performance, which retains the cutting tool original hardness and accordingly reduces the severe rubbing of the workpiece with the flank face.

There is no clear physical evidence in the open literature proving that MWCNTs nano-fluid offers better tribological properties than $\mathrm{Al}_{2} \mathrm{O}_{3}$. Thus, studying and analyzing the nano-cutting fluid heat transfer and frictional mechanisms is required, to physically investigate and emphasize this point. It is concluded that MWCNTs and $\mathrm{Al}_{2} \mathrm{O}_{3}$ nanoparticles, improve the thermal and tribological properties of the resultant nano-fluid compared with the base fluid. Thus, the obtained results showed improvements in the cutting performance of Inconel 718 (i.e., surface quality and energy consumption). In terms of future research, a comparative study between MQL-nano-fluid and other cooling and lubrication strategies, such as cryogenic cooling is required to evaluate the effectiveness of the current approach. 
Author Contributions: H.H. designed, performed relevant experiments and wrote the manuscript; H.A.K. supervised the experiments and data analysis, and reviewed the manuscript.

Acknowledgments: The authors acknowledge the support of the Natural Sciences and Engineering Research Council of Canada (NSERC).

Conflicts of Interest: The authors declare no conflict of interest.

\section{References}

1. Jafarian, F.; Umbrello, D.; Golpayegani, S.; Darake, Z. Experimental investigation to optimize tool life and surface roughness in Inconel 718 machining. Mater. Manuf. Process. 2016, 31, 1683-1691. [CrossRef]

2. Akhtar, W.; Sun, J.; Chen, W. Effect of machining parameters on surface integrity in high speed milling of super alloy GH4169/Inconel 718. Mater. Manuf. Process. 2016, 31, 620-627. [CrossRef]

3. Miller, S. Advanced materials mean advanced engines. Interdiscip. Sci. Rev. 1995, 20, 117-129. [CrossRef]

4. Davim, J.P. Machining of Hard Materials; Springer Science \& Business Media: Berlin, Germany, 2011.

5. Amrita, M.; Srikant, R.; Sitaramaraju, A. Performance evaluation of nanographite-based cutting fluid in machining process. Mater. Manuf. Process. 2014, 29, 600-605. [CrossRef]

6. Khandekar, S.; Sankar, M.R.; Agnihotri, V.; Ramkumar, J. Nano-cutting fluid for enhancement of metal cutting performance. Mater. Manuf. Process. 2012, 27, 963-967. [CrossRef]

7. Li, B.; Li, C.; Zhang, Y.; Wang, Y.; Jia, D.; Yang, M.; Zhang, N.; Wu, Q.; Han, Z.; Sun, K. Heat transfer performance of MQL grinding with different nanofluids for Ni-based alloys using vegetable oil. J. Clean. Prod. 2017, 154, 1-11. [CrossRef]

8. Davim, J.P.; Sreejith, P.; Silva, J. Turning of brasses using minimum quantity of lubricant (MQL) and flooded lubricant conditions. Mater. Manuf. Process. 2007, 22, 45-50. [CrossRef]

9. Emami, M.; Sadeghi, M.; Sarhan, A.A. Investigating the effects of liquid atomization and delivery parameters of minimum quantity lubrication on the grinding process of $\mathrm{Al}_{2} \mathrm{O}_{3}$ engineering ceramics. J. Manuf. Process. 2013, 15, 374-388. [CrossRef]

10. Kalita, P.; Malshe, A.P.; Kumar, S.A.; Yoganath, V.; Gurumurthy, T. Study of specific energy and friction coefficient in minimum quantity lubrication grinding using oil-based nanolubricants. J. Manuf. Process. 2012, 14, 160-166. [CrossRef]

11. Nanomaterials, U.R. The Advanced Nanomaterials Provider. US Research Nanomaterials; US Research Nanomaterials, Inc.: Houston, TX, USA, 2009.

12. Adams, M. ACCURATUS, Materials; ACCURATUS: Eagan, MN, USA, 2013.

13. Nam, J.S.; Lee, P.H.; Lee, S.W. Experimental characterization of micro-drilling process using nanofluid minimum quantity lubrication. Int. J. Mach. Tools Manuf. 2011, 51, 649-652. [CrossRef]

14. Lee, P.H.; Nam, J.S.; Li, C.; Lee, S.W. An experimental study on micro-grinding process with nanofluid minimum quantity lubrication (MQL). Int. J. Precis. Eng. Manuf. 2012, 13, 331-338. [CrossRef]

15. Kim, J.S.; Kim, J.W.; Lee, S.W. Experimental characterization on micro-end milling of titanium alloy using nanofluid minimum quantity lubrication with chilly gas. Int. J. Adv. Manuf. Technol. 2017, 91, 2741-2749. [CrossRef]

16. Hegab, H.; Kishawy, H.A.; Gadallah, M.H.; Umer, U.; Deiab, I. On machining of Ti-6Al-4V using multi-walled carbon nanotubes-based nano-fluid under minimum quantity lubrication. Int. J. Adv. Manuf. Technol. 2018, 97, 1593-1603. [CrossRef]

17. Hegab, H.; Umer, U.; Deiab, I.; Kishawy, H. Performance evaluation of Ti-6Al-4V machining using nano-cutting fluids under minimum quantity lubrication. Int. J. Adv. Manuf. Technol. 2018, 95, 4229-4241. [CrossRef]

18. Hegab, H.; Umer, U.; Soliman, M.; Kishawy, H.A. Effects of nano-cutting fluids on tool performance and chip morphology during machining Inconel 718. Int. J. Adv. Manuf. Technol. 2018, 96, 3449-3458. [CrossRef]

19. Raju, R.A.; Andhare, A.; Sahu, N.K. Performance of multi-walled carbon nanotube-based nanofluid in turning operation. Mater. Manuf. Process. 2017, 32, 1490-1496. [CrossRef]

20. El-Bestawi, M.A.; El-Wardany, T.I.; Yan, D.; Tan, M. Performance of whisker-reinforced ceramic tools in milling nickel-based superalloy. CIRP Ann. Manuf. Technol. 1993, 42, 99-102. [CrossRef]

21. Bhatt, A.; Attia, H.; Vargas, R.; Thomson, V. Wear mechanisms of WC coated and uncoated tools in finish turning of Inconel 718. Tribol. Int. 2010, 43, 1113-1121. [CrossRef] 
22. Prabhu, S.; Uma, M.; Vinayagam, B. Surface roughness prediction using Taguchi-fuzzy logic-neural network analysis for CNT nanofluids based grinding process. Neural Comput. Appl. 2015, 26, 41-55. [CrossRef]

23. Krajnik, P.; Pusavec, F.; Rashid, A. Nanofluids: Properties, applications and sustainability aspects in materials processing technologies. In Advances in Sustainable Manufacturing; Springer: Berlin/Heidelberg, Germany, 2011; pp. 107-113.

24. Byrne, D.M. The Taguchi approach to parameter design. Qual. Prog. 1987, 20, 19-26.

25. Rabiei, F.; Rahimi, A.; Hadad, M. Performance improvement of eco-friendly MQL technique by using hybrid nanofluid and ultrasonic-assisted grinding. Int. J. Adv. Manuf. Technol. 2017, 93, 1001-1015. [CrossRef]

26. Krishna, P.V.; Srikant, R.; Rao, D.N. Experimental investigation on the performance of nanoboric acid suspensions in SAE-40 and coconut oil during turning of AISI 1040 steel. Int. J. Mach. Tools Manuf. 2010, 50, 911-916. [CrossRef]

27. Prasad, M.; Srikant, R. Performance evaluation of nano graphite inclusions in cutting fluids with MQL technique in turning of AISI 1040 steel. Int. J. Res. Eng. Technol. 2013, 2, 381-393.

28. Sayuti, M.; Sarhan, A.A.; Hamdi, M. An investigation of optimum $\mathrm{SiO}_{2}$ nanolubrication parameters in end milling of aerospace Al6061-T6 alloy. Int. J. Adv. Manuf. Technol. 2013, 67, 833-849. [CrossRef]

29. Rahmati, B.; Sarhan, A.A.; Sayuti, M. Investigating the optimum molybdenum disulfide $\left(\mathrm{MoS}_{2}\right)$ nanolubrication parameters in CNC milling of AL6061-T6 alloy. Int. J. Adv. Manuf. Technol. 2014, 70, 1143-1155. [CrossRef]

30. Sharma, P.; Sidhu, B.S.; Sharma, J. Investigation of effects of nanofluids on turning of AISI D2 steel using minimum quantity lubrication. J. Clean. Prod. 2015, 108, 72-79. [CrossRef]

31. Revuru, R.S.; Pasam, V.K.; Syed, I.; Paliwal, U.K. Development of finite element based model for performance evaluation of nano cutting fluids in minimum quantity lubrication. CIRP J. Manuf. Sci. Technol. 2018, 21, 75-85. [CrossRef]

32. Eltaggaz, A.; Hegab, H.; Deiab, I.; Kishawy, H.A. Hybrid nano-fluid-minimum quantity lubrication strategy for machining austempered ductile iron (ADI). Int. J. Interact. Des. Manuf. 2018, 1-9. [CrossRef]

33. Eltaggaz, A.; Zawada, P.; Hegab, H.A.; Deiab, I.; Kishawy, H.A. Coolant strategy influence on tool life and surface roughness when machining ADI. Int. J. Adv. Manuf. Technol. 2018, 94, 3875-3887. [CrossRef]

34. Loos, M. Carbon Nanotube Reinforced Composites: CNT Polymer Science and Technology; Elsevier: New York, NY, USA, 2014.

(c) 2018 by the authors. Licensee MDPI, Basel, Switzerland. This article is an open access article distributed under the terms and conditions of the Creative Commons Attribution (CC BY) license (http://creativecommons.org/licenses/by/4.0/). 